\title{
Retrospective Evaluation of 85 Patients with Carotid Endarterectomy: Results of Different Techniques
}

\author{
๑ Cihan Yücel, ๑ Serkan Ketenciler, ๑ Melek Yılmaz, ๑ Nihan Kayalar
}

University of Health Sciences Turkey, Prof. Dr. Cemil Taşçığlu City Hospital, Clinic of Cardiovascular Surgery, İstanbul, Turkey

\begin{abstract}
Objectives: Carotid endarterectomy (CEA) is a safe and effective surgical technique that prevents stroke in symptomatic and asymptomatic patients with severe internal carotid artery (ICA) stenosis. However, this surgical procedure is associated with a perioperative stroke risk of $2-7.5 \%$. In this study, we examined the characteristics and early results of patients who underwent surgery for carotid artery stenosis in light of the current literature.

Materials and Methods: We retrospectively evaluated the data of patients who were diagnosed with symptomatic and asymptomatic ICA stenosis between January 2019 and January 2020 and underwent CEA in our hospital. A total of 85 patients were included in the study.

Results: The mean age of the patients was $67 \pm 8.2$ years and $72.9 \%$ of the patients were male. The most common accompanying risk factors were smoking (64.7\%) and hypertension (61.1\%). Majority of patients had CEA for symptomatic carotid disease. One patient (1.1\%) developed temporary hemiparesis. One patient (1.1\%) developed transient ischemic attack. Six patients (7\%) developed a postoperative hematoma and subsequently required revision. There was no mortality associated with the procedure.

Conclusion: Carotid artery surgery is a reliable method with low mortality and morbidity rates especially in those centers with high numbers and experienced surgical teams. A team approach including anesthetists, neurologists and interventional radiologists or interventional vascular surgeons is the key to critical decision making and the success.
\end{abstract}

Keywords: Carotid endarterectomy, near-infrared spectroscopy, carotid artery stenosis

\footnotetext{
Address for Correspondence: Cihan Yücel, University of Health Sciences Turkey, Prof. Dr. Cemil Taşçığlu City Hospital, Clinic of Cardiovascular Surgery, İstanbul, Turkey

e-mail: cihanyucell@hotmail.com ORCID: orcid.org/0000-0002-1941-0873

Received: 30.05.2020 Accepted: 23.09.2020
}

Cite this article as: Yücel C, Ketenciler S, Y1lmaz M, Kayalar N. Retrospective Evaluation of 85 Patients with Carotid

Endarterectomy: Results of Different Techniques. EJCM 2020;8(4):165-170.

DOI: $10.32596 /$ ejcm.galenos.2020.05.026

${ }^{\circ}$ Copyright 2020 by Heart and Health Foundation of Turkey (TÜSAV) / E Journal of Cardiovascular Medicine published by Galenos Publishing House. 


\section{Introduction}

Atherosclerosis of the supra-aortic vessels, especially involvement of the bifurcation of the common carotid artery (CCA), is a significant cause of recurrent ischemic strokes. These make up $20 \%$ of all strokes, and the mortality rate ranges from $10 \%$ to $30 \%$. Studies have found that the 5-year probability of developing ipsilateral stroke is $4 \%$ for patients with $50 \%$ asymptomatic carotid artery stenosis (ACAS) and $8 \%$ for patients with $70 \%$ $\operatorname{ACAS}^{(1)}$.

Carotid endarterectomy (CEA) is a safe and effective surgical technique that prevents stroke in symptomatic and asymptomatic patients with severe internal carotid artery (ICA) stenosis ${ }^{(2)}$. The effectiveness of CEA in preventing stroke in patients with symptomatic carotid stenosis has been repeatedly confirmed in major clinical trials, but most significantly by the North American Symptomatic CEA Trial (NASCET) 1 and The European Carotid Surgery Trial ${ }^{(3)}$. However, this surgical procedure is associated with a perioperative stroke risk of $2-7.5 \%{ }^{(4)}$.

CEA is recommended in symptomatic patients with 70$90 \%$ carotid stenoses, provided documented procedural death/stroke rate is $<\% 6^{(5)}$.

In this study, we examined the characteristics and early results of patients who underwent surgery for carotid artery stenosis in light of the current literature.

\section{Materials and Methods}

We retrospectively evaluated the data of patients who were diagnosed with symptomatic and asymptomatic ICA stenosis between January 2019 and January 2020 and underwent CEA in our hospital. A total of 85 patients were included in the study. The study was approved by the Ethics Committee of Training and Research Hospital (no: 48670771-514.10, date: 23/06/2020) and informed consents of patients were obtained. We included patients who underwent CEA alone and excluded those with concomitant coronary artery bypass grafting.
Patients with a carotid Doppler USG showing an ICA stenosis above $50-60 \%$ underwent computed tomography angiography of the carotid artery. One patient underwent digital subtraction angiography due to a high urea/creatine levels and was subsequently scheduled for CEA. Patients with symptomatic carotid artery stenosis of $70-99 \%$ and of 50-69\% underwent carotid surgery as Class I and Class IIa indications whereas asymptomatic patients with carotid stenosis of $60-99 \%$ underwent surgery as Class IIa indication if they had suitable surgical anatomy and a life expectancy longer than 5 years ${ }^{(5)}$. In patients with bilateral lesions, the side of CEA was determined by the dominant hemisphere or the severity of the lesion as well as the side of symptoms if there were any.

Patients with bilateral ICA stenosis were followed strictly after the first operation but no patient had symptomatic disease.

All patients underwent a detailed preoperative cardiac evaluation. We recorded patients' neurological symptoms, comorbidities, smoking status, demographic characteristics, operative and postoperative data.

All patients were operated under general anesthesia when there were no contraindications. Invasive radial arterial pressure monitoring was performed along with standard monitorization. Cerebral oxygenation was monitored with near-infrared spectroscopy (NIRS) probes placed on the patients' frontal scalp. The results of NIRS were used to determine the need for carotid shunting. We incised the skin at the anteromedial side of the sternocleidomastoid muscle and explored and secured ICA, ECA and CCA with vascular tapes. Ten thousand units of systemic intravenous heparin were administered before the carotid arterial cross-clamp was placed with the aim of an ACT value above 200. The arteriotomy incision was started at the proximal site of carotid plaque and was extended distally to the ICA. The internal and external CEA was performed using the classic open endarterectomy technique. Arteriotomy was closed either primarily with 6-0 polypropylene sutures or by using saphenous or synthetic patch plasty technique 
in accordance to surgeon preference. The patients were extubated in the operating room or the intensive care unit depending on their hemodynamic and mental status. Patients were closely monitored in the postoperative intensive care unit for neurological problems. All patients were on dual antiplatelet therapy, $75 \mathrm{mg}$ acetylsalicylic acid and clopidogrel postoperatively.

Statine treatment was administered in all patients and carotid Doppler ultrasound was performed at the postoperative $1^{\text {st }}$ and $3^{\text {rd }}$ month follow-ups.

\section{Results}

A total of 85 patients who underwent CEA between January 2019 and January 2020 in our hospital were included in the study. The mean age of the patients was $67 \pm 8.2$ years and $72.9 \%$ of the patients were male. The most common accompanying risk factors were smoking $(64.7 \%)$ and hypertension (61.1\%). The remaining demographic features and comorbidities are presented in Table 1.

Majority of patients had CEA for symptomatic carotid

Table 1. Preoperative data of patients

\begin{tabular}{|l|l|l|}
\hline Age (years) & $67 \pm 8.2$ & $46-82$ \\
\hline Ejection fraction & $54.9 \pm 5.7$ & $45-65$ \\
\hline Variable & $\mathbf{n}$ & Total (\%) \\
\hline Sex & 62 & 72.9 \\
\hline Male & 23 & 27.1 \\
\hline Female & 52 & 61.1 \\
\hline Hypertension & 55 & 64.7 \\
\hline Smoking & 48 & 56.4 \\
\hline Diabetes mellitus & 29 & 34.1 \\
\hline Coronary artery disease & 16 & 18.8 \\
\hline COPD & & \\
\hline Symptom & 29 & 34.1 \\
\hline Stroke & 20 & 23.5 \\
\hline TIA & 36 & 42.4 \\
\hline Asymptomatic & 28 & 32.9 \\
\hline Bilateral lesion & 36 & 42.4 \\
\hline Right endarterectomy & 49 & 57.6 \\
\hline Left endarterectomy & & \\
\hline $\begin{array}{l}\text { COPD: Chronic obstructive pulmonary } \text { disease, } \\
\text { attack, } n: \text { Number }\end{array}$ & Transient ischemic \\
\hline & & \\
\hline
\end{tabular}

disease. There was a history of cerebrovascular event in 29 patients $(34.1 \%)$ and a history of transient ischemic attack in 20 patients (23.5\%) whereas 36 patients (42.4\%) were asymptomatic. Bilateral ICA stenosis was present in 28 patients $(32.9 \%)$. Twenty-four (28.2\%) patients with transient ischemic attacks and minor ischemic strokes were operated between the $3^{\text {rd }}$ to $7^{\text {th }}$ days of the ischemic event in accordance with the 2017 European Society for Vascular Surgery Guidelines ${ }^{(5)}$.

During the operation, we used NIRS parameters to monitor cerebral oxygenation. We observed that the regional cerebral oxygen saturation $(\mathrm{rScO} 2)$ of five patients decreased by $25 \%$ below baseline, and subsequently placed a carotid shunt.

All patients underwent either right $(42.4 \%)$ or left $(57.6 \%)$ CEA. Operations were performed under general anesthesia in all except for two patients with contraindications. Primary closure of the arteriotomy was preferred in most patients $(87.7 \%)$. In 28 patients with bilateral carotid disease, CEA was performed on the left side in 18 patients and on the right side in 10 patients.

Arteriotomy closure was done with saphenous vein patch in 19 cases. Two of these cases were re-explored for bleeding revision. Other complications occurred in cases that underwent primary closure.

One patient (1.1\%) developed temporary hemiparesis. The symptoms resolved completely on the postoperative day 3. The subsequent brain diffusion MRI examination of the patient did not reveal any pathologies. One patient $(1.1 \%)$ developed transient ischemic attack. Six patients $(7 \%)$ developed a postoperative hematoma and subsequently required revision. There was no mortality associated with the procedure. The mean length of hospital stay was $3.4 \pm 1.2$ days. All intraoperative and postoperative data are presented in Table 2 .

\section{Discussion}

Carotid artery stenosis is an important health issue due to high rates of complications such as stroke and subsequent mortality. Stroke is the third leading cause 
Table 2. Operative and postoperative data of patients

\begin{tabular}{|c|c|c|}
\hline Variable & $\mathbf{n}$ & Total (\%) \\
\hline \multicolumn{3}{|l|}{ Side of endarterectomy } \\
\hline Right & 36 & 43.4 \\
\hline Left & 49 & 57.6 \\
\hline \multicolumn{3}{|l|}{ Arteriotomy closure } \\
\hline Primary & 66 & 87.7 \\
\hline Patch & 19 & 12.3 \\
\hline Shunt use & 5 & 5.5 \\
\hline Postoperative complications & 0 & 0 \\
\hline \multicolumn{3}{|l|}{ Permanent cerebrovascular event } \\
\hline Hemiparesis & 1 & 1.1 \\
\hline TIA & 1 & 1.1 \\
\hline Exploration for bleeding/hematoma & 6 & 7 \\
\hline Mortality & 0 & 0 \\
\hline Variable & \multicolumn{2}{|c|}{ Mean \pm SD (range) } \\
\hline Clamp duration (minutes) & \multicolumn{2}{|c|}{$23 \pm 5.7(9-35)$} \\
\hline ICU stay (days) & \multicolumn{2}{|c|}{$1.14 \pm 0.44(1-3)$} \\
\hline Hospital stay (days) & \multicolumn{2}{|c|}{$3.48 \pm 1.2(2-8)$} \\
\hline
\end{tabular}

of death worldwide and $85 \%$ of strokes are ischemic ${ }^{(6)}$. Approximately $15-20 \%$ of ischemic strokes are caused by ICA disease ${ }^{(7)}$.

Since first performed by De Bakey ${ }^{(8)}$, CEA has been accepted as a safe and effective method for the treatment of carotid stenosis ${ }^{(9)}$. Recent studies recommend CEA to patients with symptomatic ICA stenosis $\geq 50 \%$ or asymptomatic ICA stenosis $\geq 60 \%$, then following by medical treatment ${ }^{(10)}$. However, the stroke and mortality rate for CEA has been reported to be around $2-7.5 \%{ }^{(4)}$. The Asymptomatic Carotid Artery Surgery Trial (ACST-1) has shown that although CEA has a $3 \%$ risk of stroke and death in asymptomatic patients, it significantly reduces the fiveyear risk of stroke compared to patients followed up with medical treatment. While none of our subjects died in this series of CEA, there was one case of hemiparesis (1.1\%) and one with temporary ischemic attack (1.1\%). These results are compatible to and are actually lower than the reported literature ${ }^{(11)}$. The main reason for this is the high number of carotid cases per year and vast experience of the team in our institution. Every case is discussed by the vascular team and appropriate approach, the side of endarterectomy and the possible need of shunt along with the proper anesthetic approach are determined by the team. Since our department is a part of a general hospital as opposed to being part of a cardiovascular hospital, we receive many patients from neurology department. Therefore, our pure carotid cases outnumber those cases with concomitant coronary bypass grafting surgery and to analyze a more homogenous group, concomitant cases were not included in the study.

Perioperative stroke, which occurs due to intraoperative embolism and hemodynamic impairment, reduces the benefit of surgery. Embolism usually occurs due to dissection, shunt placement and cross-clamping. Cerebral hypoperfusion during cross clamping may be a cause of perioperative stroke and therefore, its recognition is important, which largely depends on effective monitoring. The development of hypoperfusion may be prevented by inserting a carotid shunt. In our clinic, we do not routinely apply carotid artery shunting in operations. Since shunt placement carries a 1-3\% risk of embolism or dissection ${ }^{(12)}$, we use shunts only in certain cases. Our strategy to use shunting is when NIRS values drop by 20$25 \%$ from baseline or when the clamp time is anticipated to be long due to the anatomy of the patient and the carotid lesion. Although a detailed study is required to analyze effectiveness of NIRS monitorization to determine the need for carotid shunting, our low number of cerebrovascular complications suggest that this approach may actually have an important role during CEA and may help to avoid unnecessary shunting.

The timing of CEA is controversial. Early surgical intervention is becoming increasingly common in patients with transient ischemic attack or minor stroke. A large study consisting of 363 patients with stroke and unstable neurological deficits reported low mortality (1.6\%) when the CEA was performed during the first week and high mortality (23.3\%) when CEA was performed during the third week of the event ${ }^{(13)}$. Recent 
studies suggest that the operation should be performed shortly after the development of the cerebrovascular event, as further cerebrovascular events may occur while waiting for the operation ${ }^{(14)}$. In our clinic, we evaluate patients having cerebrovascular events together with the neurology department and schedule an operation as soon as possible according to the severity of the cerebrovascular event. We performed carotid surgery in $24(28.2 \%)$ patients between the $3^{\text {rd }}$ and $7^{\text {th }}$ days from the onset of symptoms. These patients had minor stroke or transient ischemic attack with severe carotid stenosis. Strömberg et al. ${ }^{(15)}$ reported a combined mortality and stroke rate as $3.6 \%$ for patients treated 3-7 days after qualifying event, which was lower than those treated on $0-2$ days $(11.5 \%)$ or after 14 days $(5.4 \%)$. Our strategy in this group of patients is close in-hospital observation for a few days and performing surgery within a week from the onset of symptoms.

In recent years, endovascular interventions have become more common in the treatment of carotid artery stenosis and are currently preferred for high surgical risk patients. Therefore, more and more studies compare CEA and endovascular interventions in the treatment of carotid artery stenosis. However, although current studies show CEA as the gold standard for the treatment of carotid stenosis, more clinical studies are needed for a definitive conclusion. In our hospital, every case is discussed by multidisciplinary vascular team which includes an interventional radiologist and preferred intervention is determined. In patients with high surgical risk and suitable anatomy, endovascular intervention is preferred. In "Systolic and Pulse Pressure Hemodynamic Improvement by Restoring Elasticity" (SAPPHIRE) study, conditions related to high surgical risk were defined as congestive heart failure, severe pulmonary disease, contralateral carotid occlusion, contralateral laryngeal nerve palsy, previous radical neck surgery, cervical radiation therapy, recurrent stenosis after CEA and age $>80$ years $^{(16)}$. We follow a similar approach with a few differences. Since the carotid lesions in elderly carry a heavy calcific load, if patient does not have any other risk factors and is in good clinical condition, we prefer surgery in these patients as well. In addition, in patients with total occlusion of the contralateral carotid artery, we prefer surgery if early insertion of shunt is anticipated to be possible.

\section{Conclusion}

Our clinical experience and early surgical results are consistent with the literature. Carotid artery surgery is a reliable method with low mortality and morbidity rates especially in those centers with high numbers and experienced surgical teams. A team approach including anesthetists, neurologists and interventional radiologists or interventional vascular surgeons is the key to critical decision making and the success.

\section{Ethics}

Ethics Committee Approval: This study was approved by the Ethics Committee of Prof. Dr. Cemil Taşcioğlu City Hospital (no: 48670771-514.10, date: 23/06/2020).

Informed Consent: Informed consents of patients were obtained.

Peer-review: Externally peer-reviewed.

\section{Authorship Contributions}

Surgical and Medical Practices: C.Y., S.K., M.Y., N.K., Concept: C.Y., N.K., Design: C.Y., N.K., Data Collection or Processing: C.Y., S.K., M.Y., Analysis or Interpretation: C.Y., N.K., Literature Search: C.Y., S.K., M.Y., Writing: C.Y., N.K.

Conflict of Interest: No potential conflicts of interest relevant to this article are reported.

Financial Disclosure: The authors declared that this study received no financial support.

\section{References}

1. Longstreth WT Jr1, Shemanski L, Lefkowitz D, O’Leary DH, Polak JF, Wolfson SK Jr. Asymptomatic internal carotid artery stenosis defined by ultrasound and the risk of subsequent stroke in the elderly. The Cardiovascular Health Study. Stroke 1998;29:2371-6. 
2. Barnett HJM, Taylor DW, Haynes RB, et al. Beneficial effect of carotid endarterectomy in symptomatic patients with high-grade carotid stenosis. N Engl J Med 1991;325:445-53.

3. Randomised trial of endarterectomy for recently symptomatic carotid stenosis: final results of the MRC European Carotid Surgery Trial (ECST) Lancet. 1998;351:1379-87.

4. Pugliese F, RubertoF, Tosi A, et al. Regional cerebral saturation versus transcranial Doppler during carotid endarterectomy under regional anaesthesia. Eur J Anaesthesiol 2009;26:643-7.

5. Naylor AR, Ricco JB, de Borst GJ, et al. Management of Atherosclerotic Carotid and Vertebral Artery Disease: 2017 Clinical Practice Guidelines of the European Society for Vascular Surgery. Eur J Vasc Endovasc Surg 2018;55:3-81.

6. Adams HP Jr, Bendixen BH, Kappelle LJ, et al. Classification of subtype of acuteischemicstroke. Definitionsforuse in a multicenterclinicaltrial. TOAST. Trial of Org 10172 in AcuteStrokeTreatment. Stroke 1993;24:3541.

7. Mansour MA, Mattos MA, Faught WE, et al. The natural history of moderate $(50 \%$ to $79 \%)$ internal carotid artery stenosis in symptomatic, nonhemispheric, and asymptomatic patients. J Vasc Surg 1995;21:346-56.

8. De Bakey ME. Successfull carotid endarterectomy for cerebrovascular insufficiency: Nineteen-year follow-up. JAMA 1975;233:1083-5.

9. Maharaj R. A review of recent developments in the management of carotid artery stenosis. J Cardiothorac Vasc Anesth 2008;22:277-89.
10. Eckstein HH. European Society for Vascular Surgery Guidelines on the Management of Atherosclerotic Carotid and Vertebral Artery Disease. Eur J Vasc Endovasc Surg 2018;55:1-2.

11. Halliday A, Mansfield A, Marro J, et al. Prevention of disabling and fatal strokes by successful carotid endarterectomy in patients without recent neurological symptoms: randomised controlled trial. Lancet 2004;363:1491-502.

12. Ghosh A, Elwell C, Smith M. Review article: cerebral near-infrared spectroscopy in adults: a work in progress. Anesth Analg 2012;115:137383.

13. Khanna HL, Garg AG. 774 carotid endarterectomies for strokes and transient ischaemic attacks: comparison of results of early vs. late surgery. Acta Neurochir Suppl (Wien) 1988;42:103-6.

14. Rantner B, Pavelka M, Posch L, Schmidauer C, Fraedrich G. Carotid endarterectomy after ischemic stroke--is there a justification for delayed surgery? Eur J Vasc Endovasc Surg 2005;30:36-40.

15. Strömberg S, Gelin J, Osterberg T, Bergstrom GM, Karlstrom L, Osterberg $\mathrm{K}$. Very urgent carotid endarterectomy confers increased procedural risk. Stroke 2012;43:1331-5.

16. Yadav JS, Wholey MH, Kuntz RE, et al. Protected carotid-artery stenting versus endarterectomy in high-risk patients. N Engl J Med 2004;351:1493501 . 